\title{
Application of Tukey's Test for Statistical Measurement of Percentage Indexes Derived from the Difference Between Predicted Crystallographic Data in Five Nitihf Alloys Obtained by Two Processes
}

\author{
Roniere Leite Soares \\ Federal University of Campina Grande \\ UFCG - CCT - UAEP - AEG \\ Campina Grande - Paraíba - Brazil
}

\author{
Walman Benicio De Castro \\ Federal University of Campina Grande \\ UFCG - CCT - UAEM - LaMMEA \\ Campina Grande - Paraíba - Brazil
}

\begin{abstract}
The present paper uses the Tukey test to measure the minimal significative difference (MSD) between crystallographic data predicted by non-linear mathematical models generated from graphics published by Zarinejad (2008) and Potapov (1997) on 5 nominal compositions of Ni50Ti50-xHfx .at\% substitutional alloys fused by arc melting and melt spinning processes. Results show that the calculated MSD do not represent a statistically significant difference. Therefore, it is concluded that the independent variable (Hafnium content) does not change the analysed dependent variables (lattice parameters, crystalline structure volume and monoclinic angle $\beta)$ for any fusing processes.
\end{abstract}

Keywords- ANOVA; Monoclinic; NiTiHf; Statistical test; Tukey.

\section{INTRODUCTION}

The production of shape memory effect (SME) alloys depends sensibly on particular processes that, based on the variation of parameters involved in the equipment used (maximum melting temperature, vacuum magnitude, purge intensity, purity of the metallic charges, torch exposition time, etc), can or cannot generate different crystallographic features for samples which theoretically have the same chemical compositions. In this sense, it is important to compare the obtained results through predictive modelling functions to observe whether there are any significant statistical difference capable of indicating a great variability in crystallographic characteristics, such as: lattice parameters (a b c $[\AA]$ ), cell volume (VOL $\left[\AA^{3}\right]$ ) and characteristic angle $\beta$ (beta $\left[{ }^{\circ}\right]$ ) of the monoclinic structure (space group $\mathrm{P} 12_{1} / \mathrm{m} 1$ ). In this work, they are studied as variables dependent on hafnium content, which is considered an independent variable in the nominal composition. The focus of the study is on room temperature B19' martensitic phase B19', which has a monoclinic structure (Pearson symbol $\mathrm{mP8}$ ) and is considered by the literature as an unstable phase. In addition, the five substitutional compositions $\mathrm{Ni}_{50} \mathrm{Ti}_{50-\mathrm{X}} \mathrm{Hf}_{\mathrm{X}}$.at $\%$ considered in this instance are $X=8,11,14,17$ and 20 .at\%, which were obtained by two different processes: Arc Melting (Zarinejad, 2008) [1] and Melt Spinning (Potapov, 1997) [2].

\section{PREDICTION OF THE B19' PHASE OF NI ${ }_{50} \mathrm{TI}_{50-\mathrm{X}} \mathrm{HF}_{\mathrm{X}}$.AT\% ALLOYS}

Based on the graphs by Zarinejad (2008) [1], which measurements were obtained by XRD [3] refinement method, it was possible to calculate, through numerical proportions, the equivalence of the lattice parameters $(a, b, c)$, volume of the monoclinic structure B19' and axial angle $\beta$, as shown in table 1 .

\begin{tabular}{|c|c|c|c|c|c|}
\hline $\begin{array}{c}\text { Hf } \\
(\text { at.\% })\end{array}$ & $\begin{array}{c}\mathrm{a} \\
(\AA)\end{array}$ & $\begin{array}{c}\mathrm{b} \\
(\AA)\end{array}$ & $\begin{array}{c}\mathrm{c} \\
(\AA)\end{array}$ & $\begin{array}{c}\mathrm{V} \\
\left(\AA^{3}\right)\end{array}$ & $\begin{array}{c}\beta \\
\left({ }^{\circ}\right)\end{array}$ \\
\hline 5 & 2.8228476 & 4.1605263 & 4.6628158 & 54.195804 & 98.068493 \\
\hline 10 & 2.9049668 & 4.1210526 & 4.7220216 & 55.758741 & 98.49315 \\
\hline 15 & 2.9980132 & 4.1092105 & 4.7707581 & 57.972027 & 99.189041 \\
\hline 20 & 3.0814569 & 4.0503947 & 4.8754512 & 59.807692 & 100.04657 \\
\hline
\end{tabular}

Table 1 - Values for the four compositions of $\mathrm{Ni}_{50} \mathrm{Ti}_{50-\mathrm{X}} \mathrm{Hf}_{\mathrm{X}}$.at\% alloys (Zarinejad, 2008) obtained by conventional solidification ( $X=5,10,15$ and 20 at. \%)

From the obtained results, the same variables were estimated for the five alloys of study $(X=8,11,14,17$ e 20 at.\%). From the third order nonlinear regression (shown in Figure 1) it was adopted the polynomial function $\hat{y}=\beta_{0}+$ $\beta_{1} X+\beta_{2} X^{2}+\beta_{3} X^{3} \pm \varepsilon$ for each parameter, which resulted in: $\hat{y}_{\mathrm{a}}=2,77219+0,00562 \mathrm{x}+0,00104 \mathrm{x}^{2}-2,73732 \mathrm{E}-5 \mathrm{x}^{3}\left(\mathrm{R}^{2}=1\right)$; $\hat{y}_{b}=4,30224-0,04354 \mathrm{x}+0,00354 \mathrm{x}^{2}-9,94737 \mathrm{E}-5 \mathrm{x}^{3}\left(\mathrm{R}^{2}=1\right)$ and $\hat{y}_{c}=4,52671+0,03934 x-0,00287 x^{2}+8,85679 E-5 x^{3}$ $\left(\mathrm{R}^{2}=1\right)$. The determination coefficient $\mathrm{R}^{2}$ are equal to 1 . This indicates that the proposed models are suitable to describe the phenomenon in which the parameters $a$ and c increase, while the parameter $b$ decreases. Equally, the models adopted for volume and $\beta$ angle for b19'phase presented $100 \%$ fitting. 


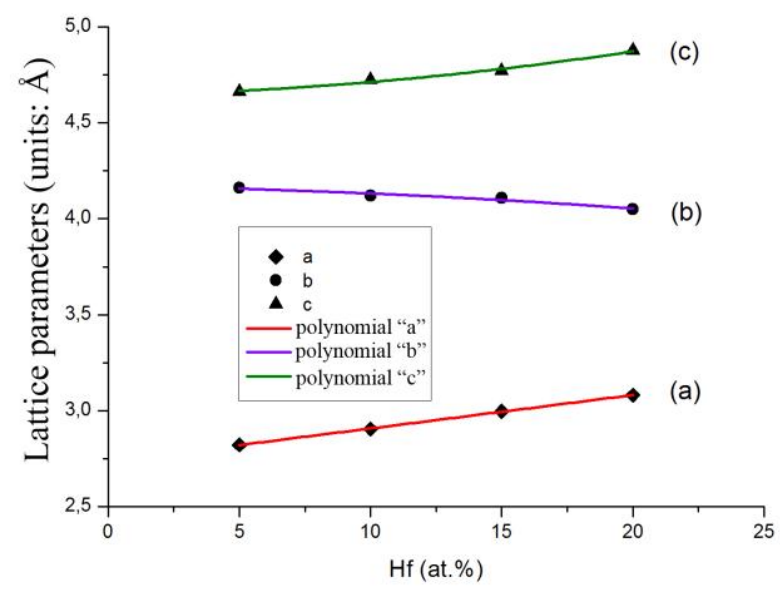

Figure 1 - Scatter diagrams \& Cubic regression curves: with the values of lattice parameters $(\mathrm{a}, \mathrm{b}, \mathrm{c})$ determined for the $\mathrm{Ni}_{50} \mathrm{Ti}_{50-\mathrm{X}} \mathrm{Hf}_{\mathrm{X}}$.at $\%$ alloys proposed by Zarinejad (2008)

All the values estimated for the five dependent variables are organized in table 2 .

\begin{tabular}{|c|c|c|c|c|c|}
\hline $\begin{array}{c}\mathrm{Hf} \\
(\mathrm{at.} \%)\end{array}$ & $\mathrm{a}(\AA)$ & $\mathrm{b}(\AA)$ & $\mathrm{c}(\AA)$ & $\begin{array}{c}\text { VOLreg }\left(\AA^{3}\right. \\
)\end{array}$ & $\mathrm{B}\left({ }^{\circ}\right)$ \\
\hline 8 & $\begin{array}{c}2.897725 \\
0\end{array}$ & $\begin{array}{c}4.1295494 \\
6\end{array}$ & $\begin{array}{c}4.7030967 \\
6\end{array}$ & 54.99855 & $\begin{array}{c}98.2847324 \\
6\end{array}$ \\
\hline 11 & $\begin{array}{c}2.996283 \\
7\end{array}$ & $\begin{array}{c}4.1192405 \\
0\end{array}$ & $\begin{array}{c}4.7300638 \\
7\end{array}$ & 56.18361 & $\begin{array}{c}98.6143636 \\
3\end{array}$ \\
\hline 14 & $\begin{array}{c}3.129822 \\
0\end{array}$ & $\begin{array}{c}4.1135641 \\
6\end{array}$ & $\begin{array}{c}4.7579803 \\
1\end{array}$ & 57.52923 & $\begin{array}{c}99.0337747 \\
7\end{array}$ \\
\hline 17 & $\begin{array}{c}3.302774 \\
5\end{array}$ & $\begin{array}{c}4.0964057 \\
1\end{array}$ & $\begin{array}{c}4.8011940 \\
9\end{array}$ & 58.81347 & $\begin{array}{c}99.5192931 \\
4\end{array}$ \\
\hline 20 & 3.519575 & 4.0516500 & 4.874053 & 59.81439 & 100.047246 \\
\hline
\end{tabular}

Table 2 - Values of the parameters predicted by the 3rd order polynomials: lattice parameters $(\mathrm{a}, \mathrm{b}, \mathrm{c})$, monoclinic volume and $\beta$, for $\mathrm{Ni}_{50} \mathrm{Ti}_{50-\mathrm{X}} \mathrm{Hf}_{\mathrm{X}} . \mathrm{at} \%$ alloys $(X=8,11,14,17$ and 20 .at \%)

A comparison between the values of table 1 and table 2, confirms a coherence in the direct proportion between the percentage of hafnium and the volume of the monoclinic structure (phase B19'). The lattice parameters for the five
$\mathrm{Ni}_{50} \mathrm{Ti}_{50-\mathrm{X}} \mathrm{Hf}_{\mathrm{X}}$.at\% Ni-rich alloys of study are plotted in figure 2:

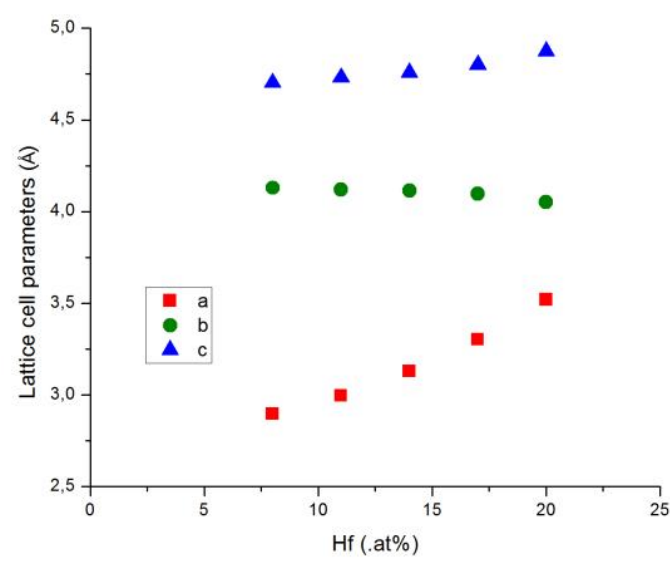

Figure 2 - Scatter Plot with estimated values of the lattice parameters of the crystal structure B19' in $\mathrm{Ni}_{50} \mathrm{Ti}_{50-\mathrm{X}} \mathrm{Hf}_{\mathrm{X}}$.at\% alloys $(\mathrm{X}=8,11,14,17,20$ at.\%)

According to Figure 3(a), from the regressive function $\quad \hat{y}_{\text {volreg }}=54,31119-0,25944 \mathrm{x}+0,05413 \mathrm{x}^{2}-$ $0,00137 \mathrm{x}^{3}\left(\mathrm{R}^{2}=1\right)$, adopted for all four Zarinejad (2008) alloys, in which $X=5,10,15$ e 20 at. $\%$, it is possible to predict the volume $\left(\AA^{3}\right)$ of the B19' monoclinic martensitic structure for the five compositions of the alloy $\mathrm{Ni}_{50} \mathrm{Ti}_{50-\mathrm{X}} \mathrm{Hf}_{\mathrm{X}}$ at.\% ( $X=8,11,1417$ and 20 at.\%), shown in Figure 3(b).

Similarly, using the cubic polynomial function $\mathrm{y}_{\beta}=$ $98,02467-0,03662 \mathrm{x}+0,00981 \mathrm{x}^{2}-1,46128 \mathrm{E}-4 \mathrm{x}^{3}\left(\mathrm{R}^{2}=1\right)$ adopted for Zarinejad alloys (2008), as seen in Figure 4(a), the $\beta$ angles of the $\mathrm{B} 19$ ' phase for the five $\mathrm{Ni}_{50} \mathrm{Ti}_{50-\mathrm{X}} \mathrm{Hf}_{\mathrm{X}}$ at. $\%$ (Hf $=8,11,14,17$ e 20 .at $\%$ ) alloys of study were predicted and plotted in figure $4(\mathrm{~b})$.


Figure 3 - Nonlinear regression (order 3) from which the volumes of the martensite phase (B19') of the five substitutive $\mathrm{Ni}_{50} \mathrm{Ti}_{50-\mathrm{x}} \mathrm{Hf}_{\mathrm{X}}$.at $\%(\mathrm{X}=8,11,14,17$ and $20 \%$.at) alloys were calculated 

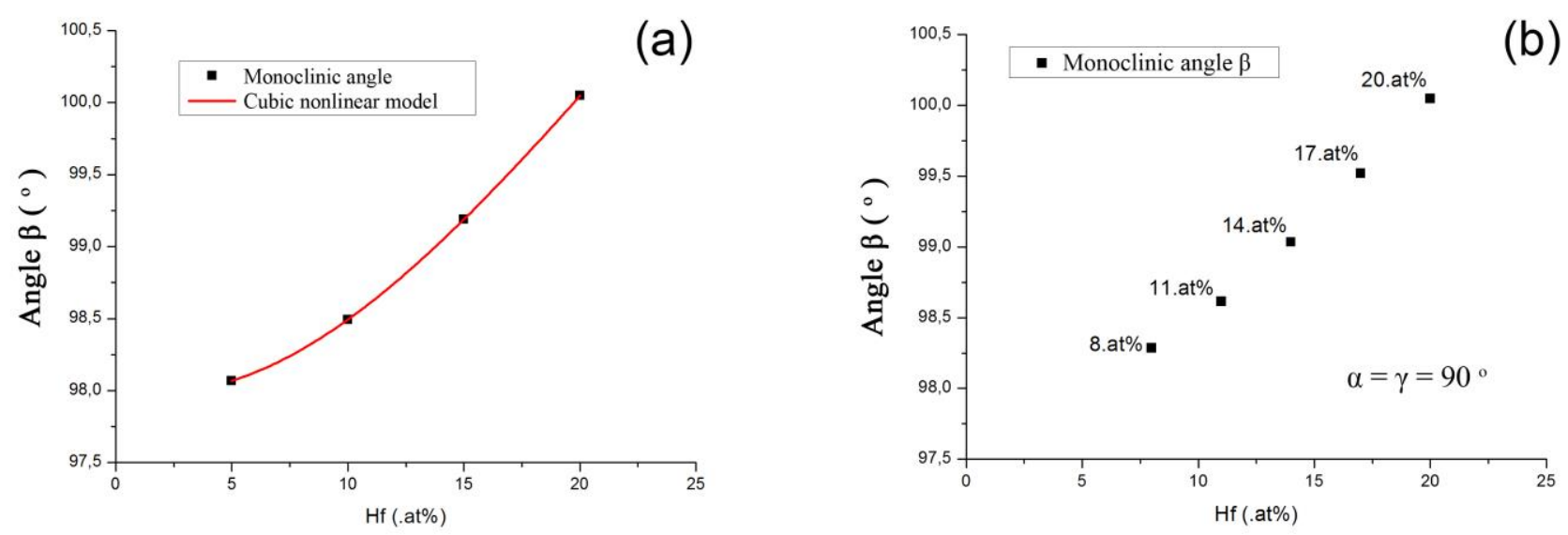

Figure 4 - Nonlinear cubic regression from which the $\beta$ angles of the $\mathrm{B} 19$ 'martensitic phases were estimated for the five $\mathrm{Ni}_{50} \mathrm{Ti}_{50-\mathrm{X}} \mathrm{Hf}_{\mathrm{X}} \cdot \mathrm{at} \%(\mathrm{X}=8,11,14,17$ and 20 at.\%) alloys rich in nickel

For the functions used as statistical models it was calculated the analysis of variance in each polynomial, according to table 3 .

\begin{tabular}{|c|c|c|c|c|c|c|}
\hline Variables & ANOVA & $D F$ & $S Q$ & $M Q$ & $F$ & Significance F \\
\hline \multirow{3}{*}{$\mathrm{a}$} & Regression & 3 & 0.03776864 & 0.012589547 & - & - \\
\hline & Residue & 0 & 0 & - & & \\
\hline & Total & 3 & 0.03776864 & & & \\
\hline \multirow{3}{*}{$\mathrm{b}$} & Regression & 3 & 0.006228132 & 0.002076044 & - & - \\
\hline & Residue & 0 & 0 & - & & \\
\hline & Total & 3 & 0.006228132 & & & \\
\hline \multirow{3}{*}{$\mathrm{c}$} & Regression & 3 & 0.024311803 & 0.008103934 & - & - \\
\hline & Residue & 0 & 0 & - & & \\
\hline & Total & 3 & 0.024311803 & & & \\
\hline \multirow{3}{*}{ Angle $\beta$} & Regression & 3 & 2.245370993 & 0.748456998 & - & - \\
\hline & Residue & 0 & 0 & - & & \\
\hline & Total & 3 & 2.245370993 & & & \\
\hline \multirow{3}{*}{$\mathrm{Vol}_{\text {Reg }}$} & Regression & 3 & 18.21455606 & 6.071518687 & - & - \\
\hline & Residue & 0 & 0 & - & & \\
\hline & Total & 3 & 18.21455606 & & & \\
\hline \multirow{3}{*}{ Vol ${ }_{\text {Calc }}$} & Regression & 3 & 18.46596165 & 6.155320551 & - & - \\
\hline & Residue & 0 & 0 & - & & \\
\hline & Total & 3 & 18.46596165 & & & \\
\hline
\end{tabular}

Table 3 - ANOVAS calculated for each model $\hat{y}=\beta_{0}+\beta_{1} x+\beta_{2} x^{2}+\beta_{3} x^{3}$ referring to the 5 variables of the B19'martensitic phase of the $5 \mathrm{Ni}_{50} \mathrm{Ti}_{50}$ ${ }_{x} \mathrm{Hf}_{\mathrm{X}}$ at. $\%$ alloys
To make explicit the coherence of the regressive model adopted for the volume, the calculated volume $(\mathrm{Vol}=$ a.b.c. $\operatorname{sen} \beta$ ) was added in Table 3, on top of which the model $\hat{\mathrm{Y}}_{\text {VOLcalc }}=53,5806847+0,018979973 \mathrm{x}+0,033586976 \mathrm{x}^{2}+$ $8,39734 \mathrm{E}-04 \mathrm{x}^{3}\left(\mathrm{R}^{2}=1\right)$ was created.

All of the $\mathrm{R}^{2}$ values were equal to 1 . This makes unnecessary the calculation of Adjusted- $\mathrm{R}^{2}$, normally used to measure the real degree of modeling reliability. According to Table 3, since there was no standard error in the coefficients, the general error of the models is 0 . For this reason, $F$ value is not presented in table 3. Thus, it can be stated that the mathematical models adopted here are statistically significant as well as predictive for all five dependent variables observed.

Taking the four Zarinejad alloys (2008) as a reference, the residues found for each regression, in each variable of the monoclinic structure B19', are presented in table 4 and figure 5 .

\begin{tabular}{|c|c|c|c|c|c|c|}
\hline Hf $($. at $\%)$ & $\mathrm{a}(\AA)$ & $\mathrm{b}(\AA)$ & $\mathrm{c}(\AA)$ & $\beta\left({ }^{\circ}\right)$ & $\mathrm{V}_{\text {regressive }}$ & Vol $_{\text {calculated }}$ \\
\hline 5 & $-1.78 \mathrm{E}-15$ & $8.88 \mathrm{E}-16$ & $1.78 \mathrm{E}-15$ & $-2.84 \mathrm{E}-14$ & $7.11 \mathrm{E}-15$ & $-2.84 \mathrm{E}-14$ \\
\hline 10 & $-8.88 \mathrm{E}-16$ & $1.78 \mathrm{E}-15$ & $2.66 \mathrm{E}-15$ & $1.42 \mathrm{E}-14$ & $1.42 \mathrm{E}-14$ & 0 \\
\hline 15 & $-8.88 \mathrm{E}-16$ & $8.88 \mathrm{E}-16$ & $1.78 \mathrm{E}-15$ & $1.42 \mathrm{E}-14$ & $1.42 \mathrm{E}-14$ & 0 \\
\hline 20 & $-8.88 \mathrm{E}-16$ & 0 & $2.66 \mathrm{E}-15$ & $1.42 \mathrm{E}-14$ & $1.42 \mathrm{E}-14$ & 0 \\
\hline
\end{tabular}

Table 4 - Residues of each variable calculated for phase B19 'of the 4 substitutive $\mathrm{Ni}_{50} \mathrm{Ti}_{50-\mathrm{X}} \mathrm{Hf}_{\mathrm{X}}$.at\% $(\mathrm{X}=5,10,15$ and 20) alloys from Zarinejad (2008) 



Figure 5 - Dispersive plot of residues in each variable of the B19'monoclinic structure (a, b, c, Volume and Beta [ $\left.\left.\beta,{ }^{\circ}\right]\right)$ for the 4 alloys of Zarinejad (2008)

\section{PREDICTION OF THE PHASE B19'ON NI ${ }_{50} \mathrm{TI}_{50-\mathrm{X}} \mathrm{HF}_{\mathrm{X}}$ .AT\% RIBBONS QUICKLY SOLIDIFIED BY MELT SPINNING}

Based on the Potapov plots (1997) for the six ribbons of substitutional compositions $\mathrm{Ni}_{49.8} \mathrm{Ti}_{50.2-\mathrm{X}} \mathrm{Hf}_{\mathrm{X}}$.at\% $(\mathrm{X}=8,9.5,11,15,20$ e 25. at\%) obtained by melt spinning, the calculation of lattice parameters (a, b, c), B19'monoclinic crystal volume and characteristic angle $\beta$ are shown in table 5:

\begin{tabular}{|c|c|c|c|c|c|}
\hline Hf $(. \mathrm{at} \%)$ & $\mathrm{a}(\AA)$ & $\mathrm{b}(\AA)$ & $\mathrm{c}(\AA)$ & $\mathrm{VOL}\left(\AA^{3}\right)$ & $\beta\left(^{\circ}\right)$ \\
\hline 8 & 2.985357 & 4.100357 & 4.725 & 56.961414 & 99.992857 \\
\hline 9.5 & 2.989285 & 4.096428 & 4.755642 & 57.337329 & 100.07142 \\
\hline 11 & 3.001071 & 4.094857 & 4.779214 & 57.769323 & 100.38571 \\
\hline 15 & 3.027785 & 4.0925 & 4.827142 & 58.499286 & 102.03571 \\
\hline 20 & 3.06000 & 4.084642 & 4.89000 & 59.539886 & 103.05714 \\
\hline 25 & 3.099285 & 4.072857 & 4.937142 & 60.25763 & 104.78571 \\
\hline
\end{tabular}

Table 5 - Crystallographic characteristics of the martensitic phase obtained by XRD refinement for the six ribbons with Potapov (1997) nominal compositions $\mathrm{Ni}_{49.8} \mathrm{Ti}_{50.2-\mathrm{x}} \mathrm{Hf}_{\mathrm{x}}$.at\% obtained by fast melt spinning solidification
Considering the similarity of the composition used by Potapov (1997) regarding the composition $\mathrm{Ni}_{50} \mathrm{Ti}_{50-\mathrm{X}} \mathrm{Hf}_{\mathrm{X}}$ .at $\%$, adopted in this work (difference of 0,2 at $\%$ in the contents of $\mathrm{Ni} \mathrm{e} \mathrm{Ti}$ ), the values of table 5 were used to proportionally calculate the same variables having as reference an alloy rich in $\mathrm{Ni}$ of nominal composition $\mathrm{Ni}_{50} \mathrm{Ti}_{50}$ ${ }_{\mathrm{X}} \mathrm{Hf}_{\mathrm{X}}$.at $\%$, quickly solidified by melt-spinning. The results are shown in Table 6:

\begin{tabular}{|c|c|c|c|c|c|}
\hline Hf $(. \mathrm{at} \%)$ & $\mathrm{a}(\AA)$ & $\mathrm{b}(\AA)$ & $\mathrm{c}(\AA)$ & $\mathrm{Vol}\left(\AA^{3}\right)$ & $\beta\left({ }^{\circ}\right)$ \\
\hline 8 & 2.99735 & 4.08402 & 4.74398 & 57.19017 & 100.39443 \\
\hline 9.5 & 3.00129 & 4.08011 & 4.77474 & 57.5676 & 100.47331 \\
\hline 11 & 3.01312 & 4.07854 & 4.79841 & 58.00133 & 100.78887 \\
\hline 15 & 3.03994 & 4.0762 & 4.84653 & 58.73422 & 102.44549 \\
\hline 20 & 3.07229 & 4.06837 & 4.90964 & 59.779 & 103.47102 \\
\hline 25 & 3.11173 & 4.05663 & 4.95697 & 60.49963 & 105.20654 \\
\hline
\end{tabular}

Table 6 - Crystallographic characteristics of the martensitic phase calculated proportionally from Potapov's ribbons $\mathrm{Ni}_{49.8} \mathrm{Ti}_{50.2-\mathrm{x}} \mathrm{Hf}_{\mathrm{x}}$.at\% (1997) for the theoretical ribbons $\mathrm{Ni}_{50} \mathrm{Ti}_{50-\mathrm{X}} \mathrm{Hf}_{\mathrm{X}}$.at\% (X=8, 9.5, 11, 15, 20 and 25 .at\%) obtained by fast melt spinning solidification 
Based on the data in table 6, these five variables were calculated with the nonlinear cubic model, which is composed by the third order function $y_{i}=\beta_{0}+\beta_{1} x_{i}+$ $\beta_{2} x_{i}^{2}+\beta_{3} x_{i}^{3}+\varepsilon_{i},(i=1,2, \ldots n)$. The values of $\mathrm{R}^{2}$ are, for the dependent variables a, b, c, volume and $\beta$, respectively, $0.9986,0.9938,0.9987,0.9986$ and 0.9885 . This certifies a large percentage of correct answers. The estimated quantities for the five compositions are presented in table 7.

\begin{tabular}{|c|c|c|c|c|c|}
\hline Hf $($. at $\%)$ & $\mathrm{a}(\AA)$ & $\mathrm{b}(\AA)$ & $\mathrm{c}(\AA)$ & $\mathrm{VOL}\left(\AA^{3}\right)$ & $\beta\left({ }^{\circ}\right)$ \\
\hline 8 & 2.995688 & 4.083342 & 4.746384 & 57.208961 & 100.237795 \\
\hline 11 & 3.012892 & 4.07906 & 4.795981 & 57.93075 & 100.997707 \\
\hline 14 & 3.031679 & 4.076048 & 4.838146 & 58.594993 & 101.835911 \\
\hline 17 & 3.051887 & 4.07311 & 4.87463 & 59.199742 & 102.726977 \\
\hline 20 & 3.073354 & 4.06905 & 4.907188 & 59.743049 & 103.645474 \\
\hline
\end{tabular}

Table 7 - Estimative of the crystallographic characteristics of the B19'phase in the five ribbons quickly solidified by melt spinning for the composition $\mathrm{Ni}_{50} \mathrm{Ti}_{50-\mathrm{X}} \mathrm{Hf}_{\mathrm{X}} \cdot$ at\% (8-20 .at\%)

Using the matrix adopted for monoclinic crystals [4], according to the Equation 01, the volumes were recalculated to show the coherence of the statistical model. The volumes found were, for the five compositions ( $\mathrm{Hf}=8,11,14,17$ and 20.at\%), in this order: 57.13535181 $\AA^{3}, 57.85901627 \AA^{3}$, $58.51514303 \AA^{3}, 59.10615326 \AA^{3}$ e $59.63533041 \AA^{3}$.

$$
V O L=\left[\left|\begin{array}{ccc}
a^{2} & 0 & a \cdot c \cdot \cos \beta \\
0 & b^{2} & 0 \\
a \cdot c \cdot \cos \beta & 0 & c^{2}
\end{array}\right|\right]^{1 / 2}
$$

The model functions were determined based on the coefficients listed in table 8 , accompanied by the respective errors.

\begin{tabular}{|c|c|c|c|c|c|c|c|c|}
\hline $\begin{array}{l}\text { Coeffici } \\
\text { ents }\end{array}$ & $\beta_{0}$ & $\beta_{0}$ & $\beta_{1}$ & $\beta_{1}$ & $\beta_{2}$ & $\beta_{2}$ & $\beta_{3}$ & $\beta_{3}$ \\
\hline Sum & Value & $\begin{array}{c}\text { Erro } \\
\pm \\
\end{array}$ & Value & $\begin{array}{c}\text { Erro } \\
\pm \\
\end{array}$ & Value & Erro \pm & Value & Erro \pm \\
\hline $\mathrm{a}$ & $\begin{array}{c}2.958 \\
78\end{array}$ & $\begin{array}{c}0.034 \\
34\end{array}$ & $\begin{array}{c}0.003 \\
71\end{array}$ & $\begin{array}{c}0.007 \\
16\end{array}$ & $\begin{array}{c}1.21 \mathrm{E}- \\
04\end{array}$ & $\begin{array}{c}4.61 \mathrm{E} \\
-04\end{array}$ & $\begin{array}{c}- \\
1.00 \mathrm{E}- \\
06\end{array}$ & $\begin{array}{c}9.25 \mathrm{E} \\
-06\end{array}$ \\
\hline b & $\begin{array}{c}4.110 \\
06\end{array}$ & $\begin{array}{c}0.015 \\
79\end{array}$ & $\begin{array}{c}- \\
0.005 \\
38\end{array}$ & $\begin{array}{c}0.003 \\
29\end{array}$ & $\begin{array}{c}3.14 \mathrm{E}- \\
04\end{array}$ & $\begin{array}{c}2.12 \mathrm{E} \\
-04\end{array}$ & $\begin{array}{c}- \\
7.38 \mathrm{E}- \\
06\end{array}$ & $\begin{array}{c}4.25 \mathrm{E} \\
-06\end{array}$ \\
\hline c & $\begin{array}{c}4.564 \\
45\end{array}$ & $\begin{array}{c}0.058 \\
9\end{array}$ & $\begin{array}{c}0.028 \\
21\end{array}$ & $\begin{array}{c}0.012 \\
29\end{array}$ & $\begin{array}{c}- \\
7.70 \mathrm{E}- \\
04 \\
\end{array}$ & $\begin{array}{c}7.90 \mathrm{E} \\
-04\end{array}$ & $\begin{array}{c}1.08 \mathrm{E}- \\
05\end{array}$ & $\begin{array}{c}1.59 \mathrm{E} \\
-05\end{array}$ \\
\hline Volume & $\begin{array}{c}55.01 \\
768\end{array}$ & $\begin{array}{c}0.964 \\
61\end{array}$ & $\begin{array}{c}0.297 \\
08\end{array}$ & $\begin{array}{c}0.201 \\
2\end{array}$ & $\stackrel{-}{0.0028}$ & $\begin{array}{c}0.012 \\
94\end{array}$ & $\begin{array}{c}- \\
1.20 \mathrm{E}- \\
05\end{array}$ & $\begin{array}{c}2.60 \mathrm{E} \\
-04\end{array}$ \\
\hline$\beta$ & $\begin{array}{c}98.78 \\
753\end{array}$ & $\begin{array}{c}4.197 \\
37\end{array}$ & $\begin{array}{c}0.115 \\
09\end{array}$ & $\begin{array}{c}0.875 \\
51\end{array}$ & $\begin{array}{c}0.0095 \\
3\end{array}$ & $\begin{array}{c}0.056 \\
3\end{array}$ & $\begin{array}{c}- \\
1.57 \mathrm{E}- \\
04\end{array}$ & $\begin{array}{c}0.001 \\
13\end{array}$ \\
\hline
\end{tabular}

Table 8 - Coefficient values calculated for third order statistical models for $\mathrm{Ni}_{50} \mathrm{Ti}_{50-\mathrm{X}} \mathrm{Hf}_{\mathrm{X}}$. at $\%$
For each of the cubic functions, the values of Adjusted- $\mathrm{R}^{2}$ computed are, in the decrescent order, in table 8: $0.99643,0.98445,0.99682,0.99658$ e 0.97115 .
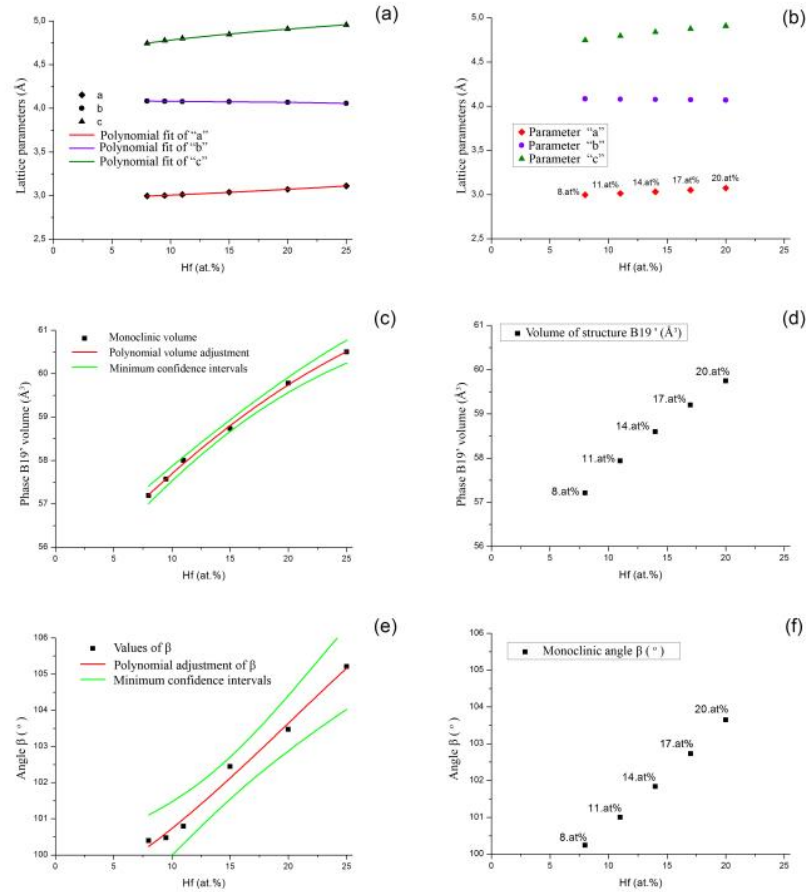

Figure 6 - Left column presents the graphs with estimated values for the six Potapov ribbons (1997), and right column shows the calculated values for the five theoretical ribbons of nominal compositions $\mathrm{Ni}_{50} \mathrm{Ti}_{50-\mathrm{x}} \mathrm{Hfx}$.at $\%$

For a graphic visualization, figure 6 presents the values calculated for the six Potapov ribbons (1997) plotted in the left column (figure 6(a), figure 6(c) and figure 6(e)) in a way that they are compared with the values predicted for the five ribbons studied here, plotted in the right column (figure 6(b), figure 6(d) and figure 6(f)).

According to the obtained numbers, the values of $\beta$ angle, volume and "a" and "c" are directly proportional to the atomic percentage of hafnium from the alloy, except in the lattice parameter "b", which is inversely proportional to the content of Hf (.at\%)

\section{COMPARISON OF CRYSTALLOGRAPHIC CHARACTERISTICS OF THE MARTENSITIC PHASE IN ZARINEJAD'S ALLOYS AND POTAPOV'S RIBBONS}

Due to the fact that these variables are different, i.e., one-dimensional (lattice parameters) two-dimensional $(\beta$ angles) and three-dimensional (monoclinic structures volumes) entities. To enable a dimensionless comparison between the predicted data from Zarinejad (2008) and Potapov (1997), it was necessary to consider the percentage indexess of the differences between the estimated values for each parameter $(a, b, c, V o l$ e $\beta$ ) of the five compositions $\mathrm{Ni}_{50} \mathrm{Ti}_{50-\mathrm{XHf}}$.at\%. This makes them arbitrary data Therefore, it was necessary to organize the sample series from table 11 with the dimensionless format of table 9 Percentage indices have arbitrary units. 
Using descriptive statistics, the measures of central tendency and dispersion were summarized in table 10 .

The normal distribution (differences percentage indexes versus $x$ indexes' density) is represented by equation 2 and plotted in figure 7. It is composed of: $\sigma$ (standard deviation), $e$ (Constante de Euler-Mascheroni: 2.718), $\pi$ (proportion) and $\mu$ (population mean).

\begin{tabular}{|c|c|c|c|c|}
\hline \multicolumn{5}{|c|}{ Percentage indexes ranked in ascending order } \\
\hline 0.0012 & 0.0068 & 0.0137 & 0.0236 & 0.0327 \\
\hline 0.0043 & 0.0091 & 0.0151 & 0.0275 & 0.0347 \\
\hline 0.0055 & 0.0091 & 0.0166 & 0.0302 & 0.0386 \\
\hline 0.0057 & 0.0098 & 0.0182 & 0.0312 & 0.076 \\
\hline 0.0065 & 0.0112 & 0.0195 & 0.0314 & 0.1268 \\
\hline
\end{tabular}

Table 9 - List of 25 data organized sequentially (indexes of dimensional differences verified between both authors)

\begin{tabular}{|c|c|c|c|c|c|}
\hline Mean (average) & 0.0242 & Standard deviation & 0.0267 & Interval & 0.1256 \\
\hline Standard error & 0.0053 & Sample variance & 0.0007 & Min and Max & $0.0012 ; 0.1268$ \\
\hline Median & 0.0166 & Kurtosis & 9.1143 & Sum & 0.605 \\
\hline Mode (fashion) & 0.0091 & Asymmetry & 2.7719 & Confidence level $(95 \%)$ & 0.011025366 \\
\hline
\end{tabular}

Table 10 - Descriptive summary of the main statistical measurements

$$
f(x)=\frac{1}{\sigma \sqrt{2 \pi}} e^{-\frac{1}{2}\left(\frac{x-\mu}{\sigma}\right)^{2}}, \quad X \in(-\infty, \infty)
$$

It is noticeable, in figure 7 , that there is a concentration of minor differences close to bigger densities. This certifies that the values from both authors are close.

\begin{tabular}{|c|c|c|c|c|c|c|c|c|c|c|c|}
\hline \multicolumn{2}{|c|}{ Characteristics of phase B19' (monoclinic) } & Zarinejad & Potapov & Zarinejad & Potapov & Zarinejad & Potapov & Zarinejad & Potapov & Zarinejad & Potapov \\
\hline Hf $(. a \%)$ & $\hat{\mathrm{y}}$ & \multicolumn{2}{|c|}{$\mathrm{a}$} & \multicolumn{2}{|c|}{$\mathrm{b}$} & \multicolumn{2}{|c|}{$\mathrm{c}$} & \multicolumn{2}{|c|}{ VOL } & \multicolumn{2}{|c|}{$\beta$} \\
\hline \multirow{5}{*}{8} & Estimated values & 2.897 .725 & 2.995 .688 & 4.129 .549 & 4.083 .342 & 4.703 .097 & 4.746 .384 & 5.499 .855 & 5.720 .896 & 9.828 .473 & 1.002 .378 \\
\hline & Absolute difference $(\AA)$ & \multicolumn{2}{|c|}{0.097963} & \multicolumn{2}{|c|}{0.046207} & \multicolumn{2}{|c|}{0.043287} & \multicolumn{2}{|c|}{2.210 .411} & \multicolumn{2}{|c|}{1.953 .065} \\
\hline & Proximity $(\%)$ & \multicolumn{2}{|c|}{$96.73 \%$} & \multicolumn{2}{|c|}{$98.88 \%$} & \multicolumn{2}{|c|}{$99.09 \%$} & \multicolumn{2}{|c|}{$96.14 \%$} & \multicolumn{2}{|c|}{$98.05 \%$} \\
\hline & Mean & \multicolumn{2}{|c|}{29.467 .065} & \multicolumn{2}{|c|}{41.064 .455} & \multicolumn{2}{|c|}{47.247 .405} & \multicolumn{2}{|c|}{561.037 .555} & \multicolumn{2}{|c|}{992.612 .625} \\
\hline & Percentage difference & \multicolumn{2}{|c|}{$3.27 \%$} & \multicolumn{2}{|c|}{$1.12 \%$} & \multicolumn{2}{|c|}{$0.91 \%$} & \multicolumn{2}{|c|}{$3.86 \%$} & \multicolumn{2}{|c|}{$1.95 \%$} \\
\hline \multirow{5}{*}{11} & Estimated values & 2.996 .284 & 3.012 .892 & 4.119 .241 & 407.906 & 4.730 .064 & 4.795 .981 & 5.618 .361 & 5.793 .075 & 9.861 .436 & 1.009 .977 \\
\hline & Absolute difference $(\AA)$ & \multicolumn{2}{|c|}{0.016608} & \multicolumn{2}{|c|}{0.040181} & 0.00 & 917 & 174 & 714 & 2.38 & .347 \\
\hline & Proximity $(\%)$ & 99. & & & $2 \%$ & & & & & & \\
\hline & Mean & 3.00 & .588 & 40.9 & 1.505 & 47.6 & 0.225 & 5.70 & 718 & 998.0 & 0.335 \\
\hline & Percentage difference & & & & & & & & & & \\
\hline & Estimated values & 3.129 .822 & 3.031 .679 & 4.113 .564 & 4.076 .048 & 475.798 & 4.838 .146 & 5.752 .923 & 5.859 .499 & 9.903 .377 & 1.018 .359 \\
\hline & Absolute difference $(\AA)$ & 0.09 & 143 & 0.0 & 516 & 0.08 & 166 & 1.06 & 763 & 2.80 & .141 \\
\hline 14 & Proximity $(\%)$ & 96. & & & $9 \%$ & & $4 \%$ & & & 97. & $5 \%$ \\
\hline & Mean & 30.80 & 7.505 & 4.09 & 806 & 4.79 & .063 & 580.6 & 1.115 & 1.004. & 48.405 \\
\hline & Percentage difference & & & & & & & & & & \\
\hline & Estimated values & 3.302 .775 & 3.051 .887 & 4.096 .406 & 407.311 & 4.801 .194 & 487.463 & 5.881 .347 & 5.919 .974 & 9.951 .929 & 102.727 \\
\hline & Absolute difference $(\AA)$ & 3.30 & .775 & 4.09 & 406 & 4.80 & .194 & 5.88 & 347 & 9.95 & .929 \\
\hline 17 & Proximity $(\%)$ & 92. & $0 \%$ & & $3 \%$ & & $9 \%$ & & & 96. & $8 \%$ \\
\hline & Mean & 3.17 & .331 & 4.08 & 1.758 & 4.83 & 912 & 59.0 & 606 & 1.011. & 31.335 \\
\hline & Percentage difference & & & & $7 \%$ & & & & & & \\
\hline & Estimated values & 3.519 .576 & 3.073 .354 & 405.165 & 406.905 & 4.874 .053 & 4.907 .188 & 5.981 .439 & 5.974 .305 & 1.000 .472 & 1.036 .455 \\
\hline & Absolute difference $(\AA)$ & 0.44 & 222 & & 174 & 0.03 & 3135 & 0.07 & 341 & 3.59 & .274 \\
\hline 20 & Proximity $(\%)$ & 87. & & & $7 \%$ & & $2 \%$ & & & 96. & $3 \%$ \\
\hline & Mean & 3.29 & .465 & 400 & 035 & 48.9 & 6.205 & 597.7 & 7.195 & 101.8 & 6.337 \\
\hline & Percentage difference & 12. & & & & & & & & & \\
\hline
\end{tabular}

Table 11 - Comparison between $\mathrm{Ni}_{50} \mathrm{Ti}_{50-\mathrm{x}} \mathrm{Hf}_{\mathrm{X}}$.at\% alloys and ribbons based on the models by Zarinejad (2008) and Potapov (1997)

However, there is a clear comprehension that the crystallographic characteristics depend not only on the hafnium content, but they are also sensitive to the peculiarities of the two production processes as well as the typical variables of each one of them: electric arc melting (Arc Melting) and quick solidification Melt Spinning.

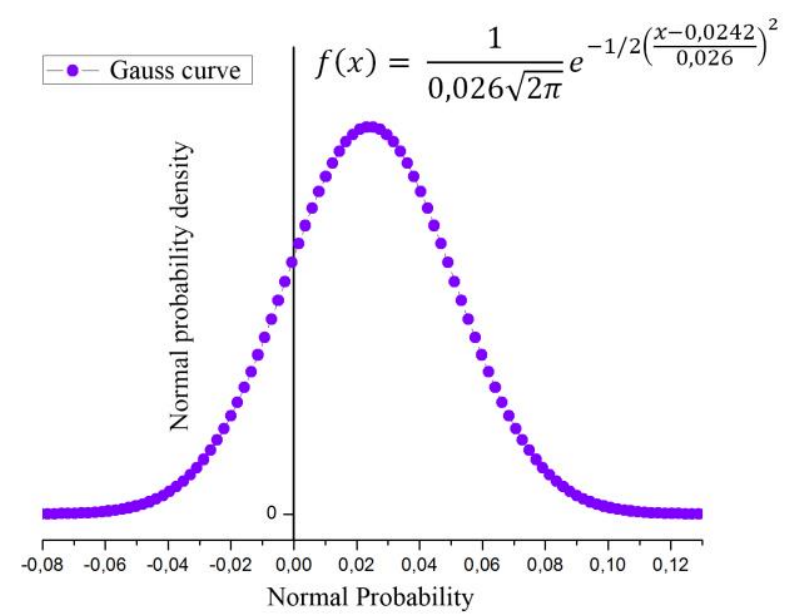

Figure 7 - Plot of the probability curve (100 points) of the difference indexes estimated by the statistical models adopted for Zarinejad alloys (2008) and Potapov ribbons (1997) 
Depending on how the peculiarities involving each one of the processes are treated, one can directly influence the main properties of the samples such as: homogeneity, amount of residual stress and minimization of oxidation, among others. These physical and mechanic properties, among others are derived from atomic arrangementknown as crystallographic structures (or crystalline structures).

It can be mentioned as variables of these processes: the number of times that the bulk was melted, exposure time to the torch, type of material of the mold, efficiency of the applied vacuum, rotating speed of the copper flywheel in quickly solidified ribbons etc. Hence, all the possibilities of variation and instrumental errors generate conditions of solidification which interfere in the micro structure of the alloys and obtained ribbons.

\section{CONCLUSIONS}

The analysis of variance (ANOVA) is an unilateral test based on the F-Snedecor table, which after calculating the F-value, it measures whether it is inside or outside of the acceptance area, according to the following hypothesis test:

$$
\left\{\begin{array}{c}
\mathrm{H}_{0}: \mu_{\text {Potapov }}=\mu_{\text {Zarinejad }} \\
\mathrm{H}_{1} \text { : there is at least one difference between the means }
\end{array}\right.
$$

As it is an OneWay ANOVA, the only factor (independent variable) is the atomic percentage of $\mathrm{Hf}(. a t \%)$. As a rule, in terms of null hypothesis $\left(\mathrm{H}_{0}\right)$, the calculated Fvalue is inside the area of acceptance, i.e., minor than critical F. Otherwise, if $\mathrm{H}_{0}$ is rejected, the alternative hypothesis $\left(\mathrm{H}_{1}\right)$ will be accepted having necessarily, the F-value calculated outside the area of acceptance, i.e., bigger than the critical F.

In this case, we considered that $\mathrm{F}(5 \%)$; DF1 (DFW); DF2 $($ DFR $)=3,12$ (tabulated), according to the standard table for Tukey's Test $(\alpha=0.05)$ [5]. According to Table 12, as the calculated $\mathrm{F}=3.13$ is bigger than the critical tabulated value, we concluded that there is a difference between the averages of both treatment groups: Potapov and Zarinejad. This conclusion is also confirmed by the P-value, which is smaller than 0.05 . The lower the P-value, lower is the possibility for $\mathrm{H}_{0}$ be true. It is important to note that $\mathrm{DF}_{1}$ [horizontal = numerator] is the degree of freedom between groups (DFW) and that $\mathrm{DF}_{2}$ [vertical = denominator] is the degree of freedom of the residues (DFR).

\begin{tabular}{|c|c|c|c|c|c|c|}
\hline $\begin{array}{c}\text { Variation } \\
\text { source }\end{array}$ & $\begin{array}{c}\text { Sum of } \\
\text { sQrs }\end{array}$ & $\mathrm{DF}$ & $\begin{array}{c}\text { Mean } \\
\text { square }\end{array}$ & $\mathrm{F}_{\text {calc }}$ & $\begin{array}{c}\text { valor-P } \\
\text { (same) }\end{array}$ & $\begin{array}{c}\text { critical } \\
\mathrm{F}_{\text {tabulated }}\end{array}$ \\
\hline $\begin{array}{c}\text { Between } \\
\text { groups: }\end{array}$ & 6739.09 & 2 & 3369.55 & 3.131 & 0.04968 & 3.123907449 \\
\hline $\begin{array}{c}\text { Within } \\
\text { groups: }\end{array}$ & 77488 & 72 & 1076.22 & \multicolumn{3}{|c|}{ Permutation $\mathrm{p}(\mathrm{n}=99999)$} \\
\hline Total: & 84227.1 & 74 & 0.04909 & \multicolumn{3}{|c|}{$\begin{array}{c}\text { Table F-Snedecor }-\mathrm{F}(5 \%): 2.74= \\
3.12\end{array}$} \\
\hline
\end{tabular}

Table 12 - OneWay ANOVA calculated for two series of samples of the crystalline dimensions of the $\mathrm{B} 19$ 'monoclinic phase in $\mathrm{Ni}_{50} \mathrm{Ti}_{50}$ ${ }_{x} \mathrm{Hf}_{\mathrm{X}}$.at $\%$ alloys and ribbons obtained by conventional and rapid solidifications (Zarinejad and Potapov, respectively)

(1) Between groups $(\mathrm{W})=$ Treatment $=$ Between treatments $=$ Between

(2) Within groups $(\mathrm{R})=$ Residue $=$ Error $=$ Within

(3) $\mathrm{DF}=$ degree of freedom

Therefore, the null hypothesis is rejected $\left(\mathrm{H}_{0}\right)$. However, to ascertain whether this difference is statistically significant, it is necessary to perform a parametric test to certify this significance. This decision was taken based on the normality test of Anderson-Darling [6], which predicts as "normal" the set of 25 data organized in table 9, as shown in figure 8:

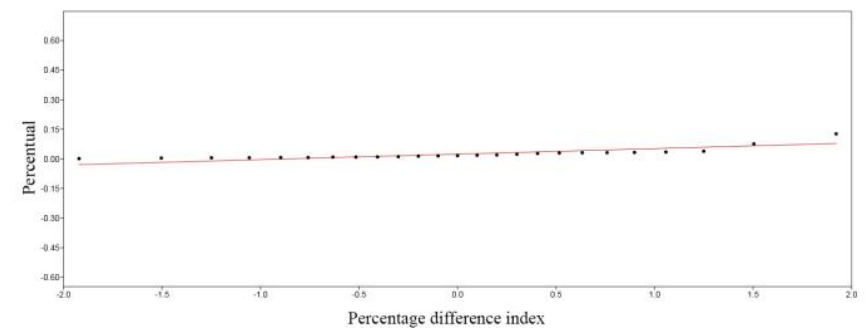

Figure 8 - Anderson-Darling Normality Test for the percentage indexes

A comparative analysis was made between two different solidification methods (arc melting e melt spin), when applying the TUKEY's Test (through table 13) [7] to, in a complementary form to ANOVA, calculate the minimum significant difference (m. s. d.) there is between the averages in the martensitic crystallographic characteristics, according to the original dimensional data predicted by the adjustment models, shown in table 2 and table 7 . It is concluded that the method to obtain the alloys doesn't interfere in the dimensions here evaluated, that is, there is no significant statistical difference. This is due to the fact that the calculated difference $\left(\left|\mu_{\text {Potapov }}-\mu_{\text {Zarinejad }}\right|\right)$ was of 0.75 . According to equation 3 , the m.s.d $[\Delta]$ necessary for both groups (data series) to have a significant difference is 19.027.

$$
\Delta=q * \sqrt{\frac{\text { Mean Square (residues) }}{\text { Number of treatment repetitions }}}
$$

In this calculation, $q[q(5 \%)$; $\mathrm{k}$; DF of residues $=$ 2.899943 ] is a tabulated value (F-Snedecor table, $\alpha=0.05$ ), the QMR is 1076.22 (highlighted in table 12) and the number of repetitions is equal to 25 . This count of 25 is contained in table 13, before the summary (resume). 


\begin{tabular}{|c|c|c|c|}
\hline $\mathrm{Hf}$ ( at. $\%$ ) & Dimensions & Zarinejad (2008) & Potapov (1997) \\
\hline \multirow{5}{*}{8} & a $(\AA)$ & 2.897725078 & 2.995688 \\
\hline & $\mathrm{b}(\AA)$ & 4.129549466 & 4.083342 \\
\hline & c $(\AA)$ & 4.703096765 & 4.746384 \\
\hline & Volume $\left(\AA^{3}\right)$ & 54.99855 & 57.208961 \\
\hline & $\beta\left({ }^{\circ}\right)$ & 98.28473246 & 100.237795 \\
\hline \multirow{5}{*}{11} & $\mathrm{a}(\AA)$ & 2.996283729 & 3.012892 \\
\hline & $\mathrm{b}(\AA)$ & 4.119240505 & 4.07906 \\
\hline & c $(\AA)$ & 4.730063875 & 4.795981 \\
\hline & Volume $\left(\AA^{3}\right)$ & 56.18361 & 57.93075 \\
\hline & $\beta\left({ }^{\circ}\right)$ & 98.61436363 & 100.997707 \\
\hline \multirow{5}{*}{14} & $\mathrm{a}(\AA)$ & 3.129822061 & 3.031679 \\
\hline & $\mathrm{b}(\AA)$ & 4.113564167 & 4.076048 \\
\hline & $c(\AA)$ & 4.757980318 & 4.838146 \\
\hline & Volume $\left(\AA^{3}\right)$ & 57.52923 & 58.594993 \\
\hline & $\beta\left({ }^{\circ}\right)$ & 99.03377477 & 101.835911 \\
\hline \multirow{5}{*}{17} & $\mathrm{a}(\AA)$ & 3.302774532 & 3.051887 \\
\hline & $\mathrm{b}(\AA)$ & 4.096405712 & 4.07311 \\
\hline & c $(\AA)$ & 4.801194093 & 4.87463 \\
\hline & Volume $\left(\AA^{3}\right)$ & 58.81347 & 59.199742 \\
\hline & $\beta\left({ }^{\circ}\right)$ & 99.51929314 & 102.726977 \\
\hline \multirow{5}{*}{20} & $\mathrm{a}(\AA)$ & 3.5195756 & 3.073354 \\
\hline & $\mathrm{b}(\AA)$ & 4.0516504 & 4.06905 \\
\hline & $\mathrm{c}(\AA)$ & 4.8740532 & 4.907188 \\
\hline & Volume $\left(\AA^{3}\right)$ & 59.81439 & 59.743049 \\
\hline & $\beta\left({ }^{\circ}\right)$ & 100.047246 & 103.645474 \\
\hline \multirow{5}{*}{ Resume } & Sum & 843.0616395 & 861.829798 \\
\hline & Mean (average) & 33.72246558 & 34.47319192 \\
\hline & Standard deviation & 39.50325635 & 40.6129109 \\
\hline & Variance & 1560.507263 & 1649.408532 \\
\hline & Difference between means & \multicolumn{2}{|c|}{$|39.05-40.61|=0.75072634$} \\
\hline
\end{tabular}

Table 13 - Paired values of the crystallographic characteristics of the $\mathrm{B} 19$ 'martensitic phase in $\mathrm{Ni}_{50} \mathrm{Ti}_{50-\mathrm{X}} \mathrm{Hf}_{\mathrm{X}}$.at\% alloys predicted by the fitting

\section{REFERENCES}

[1] Zarinejad, M., Y. Liu, and T.J. White, The crystal chemistry of martensite in NiTiHf shape memory alloys. Intermetallics, 2008. 16(7): p. 876-883.

[2] Potapov, P., et al., Effect of $\mathrm{Hf}$ on the structure of Ni-Ti martensitic alloys. Materials Letters, 1997. 32(4): p. 247-250.

[3] 3. Rietveld, H., A profile refinement method for nuclear and magnetic structures. Journal of applied Crystallography, 1969. 2(2): p. $65-71$.
[4] Koch, E., Twinning, in International Tables for Crystallography Volume C: Mathematical, physical and chemical tables. 2006, Springer. p. 10-14.

[5] Tukey, J.W., The future of data analysis. The annals of mathematical statistics, 1962. 33(1): p. 1-67.

[6] Pettitt, A., Testing the normality of several independent samples using the Anderson-Darling statistic. Journal of the Royal Statistical Society: Series C (Applied Statistics), 1977. 26(2): p. 156-161

[7] Rojas, I., et al., Analysis of the functional block involved in the design of radial basis function networks. Neural Processing Letters, 2000. 12(1): p. 1-17.

\section{ATTACHMENTS}

\begin{tabular}{|c|c|c|c|c|c|c|c|c|c|}
\hline \multirow{2}{*}{$\begin{array}{c}\text { DF } \\
(\mathrm{n}-\mathrm{k})\end{array}$} & \multicolumn{9}{|c|}{ k levels } \\
\hline & 2 & 3 & 4 & 5 & 6 & 7 & 8 & 9 & 10 \\
\hline 5 & 3.64 & 4.6 & 5.22 & 5.67 & 6.03 & 6.33 & 6.58 & 6.8 & 6.99 \\
\hline 6 & 3.46 & 4.34 & 4.9 & 5.3 & 5.63 & 5.9 & 6.12 & 6.32 & 6.49 \\
\hline 7 & 3.34 & 4.16 & 4.68 & 5.06 & 5.36 & 5.61 & 5.82 & 6 & 6.16 \\
\hline 8 & 3.26 & 4.04 & 4.53 & 4.89 & 5.17 & 5.4 & 5.6 & 5.77 & 5.92 \\
\hline 9 & 3.2 & 3.95 & 4.41 & 4.76 & 5.02 & 5.24 & 5.43 & 5.59 & 5.74 \\
\hline 10 & 3.15 & 3.88 & 4.33 & 4.65 & 4.91 & 5.12 & 5.3 & 5.46 & 5.6 \\
\hline 11 & 3.11 & 3.82 & 4.26 & 4.57 & 4.82 & 5.03 & 5.2 & 5.35 & 5.49 \\
\hline 12 & 3.08 & 3.77 & 4.2 & 4.51 & 4.75 & 4.95 & 5.12 & 5.27 & 5.39 \\
\hline 13 & 3.06 & 3.73 & 4.15 & 4.45 & 4.69 & 4.88 & 5.05 & 5.19 & 5.32 \\
\hline 14 & 3.03 & 3.7 & 4.11 & 4.41 & 4.64 & 4.83 & 4.99 & 5.13 & 5.25 \\
\hline
\end{tabular}




\begin{tabular}{|c|c|c|c|c|c|c|c|c|c|}
\hline 15 & 3.01 & 3.67 & 4.08 & 4.37 & 4.59 & 4.78 & 4.94 & 5.08 & 5.2 \\
\hline 16 & 3 & 3.65 & 4.05 & 4.33 & 4.56 & 4.74 & 4.9 & 5.03 & 5.15 \\
\hline 17 & 2.98 & 3.63 & 4.02 & 4.3 & 4.52 & 4.7 & 4.86 & 4.99 & 5.11 \\
\hline 18 & 2.97 & 3.61 & 4 & 4.28 & 4.49 & 4.67 & 4.82 & 4.96 & 5.07 \\
\hline 19 & 2.96 & 3.59 & 3.98 & 4.25 & 4.47 & 4.65 & 4.79 & 4.92 & 5.04 \\
\hline 20 & 2.95 & 3.58 & 3.96 & 4.23 & 4.45 & 4.62 & 4.77 & 4.9 & 5.01 \\
\hline 24 & 2.92 & 3.53 & 3.9 & 4.17 & 4.37 & 4.54 & 4.68 & 4.81 & 4.92 \\
\hline 30 & 2.89 & 3.49 & 3.85 & 4.1 & 4.3 & 4.46 & 4.6 & 4.72 & 4.82 \\
\hline 40 & 2.86 & 3.44 & 3.79 & 4.04 & 4.23 & 4.39 & 4.52 & 4.63 & 4.73 \\
\hline 60 & 2.83 & 3.4 & 3.74 & 3.98 & 4.16 & 4.31 & 4.44 & 4.55 & 4.65 \\
\hline 120 & 2.8 & 3.36 & 3.68 & 3.92 & 4.1 & 4.24 & 4.36 & 4.47 & 4.56 \\
\hline$\infty$ & 2.77 & 3.31 & 3.63 & 3.86 & 4.03 & 4.17 & 4.29 & 4.39 & 4.47 \\
\hline
\end{tabular}

Table 14 - Tukey test table $(\alpha=0.05)$ : degrees of freedom and levels [studentized]

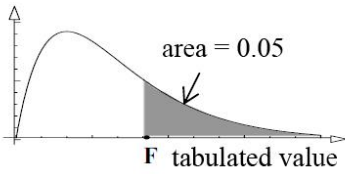

\begin{tabular}{|c|c|c|c|c|c|c|c|c|c|c|}
\hline Table VI & \multicolumn{10}{|c|}{ Degrees of Freedom (DF) in the numerator } \\
\hline DF in denominator & 1 & 2 & 3 & 4 & 5 & 6 & 7 & 8 & 9 & 10 \\
\hline 1 & 161.45 & 199.5 & 215.71 & 224.58 & 230.16 & 233.99 & 236.77 & 238.88 & 240.54 & 241.88 \\
\hline 2 & 18.51 & 19 & 19.16 & 19.25 & 19.3 & 19.33 & 19.35 & 19.37 & 19.38 & 19.4 \\
\hline 3 & 10.13 & 9.55 & 9.28 & 9.12 & 9.01 & 8.94 & 8.89 & 8.85 & 8.81 & 8.79 \\
\hline 4 & 7.71 & 6.94 & 6.59 & 6.39 & 6.26 & 6.16 & 6.09 & 6.04 & 6 & 5.96 \\
\hline 5 & 6.61 & 5.79 & 5.41 & 5.19 & 5.05 & 4.95 & 4.88 & 4.82 & 4.77 & 4.74 \\
\hline 6 & 5.99 & 5.14 & 4.76 & 4.53 & 4.39 & 4.28 & 4.21 & 4.15 & 4.1 & 4.06 \\
\hline 7 & 5.59 & 4.74 & 4.35 & 4.12 & 3.97 & 3.87 & 3.79 & 3.73 & 3.68 & 3.64 \\
\hline 8 & 5.32 & 4.46 & 4.07 & 3.84 & 3.69 & 3.58 & 3.5 & 3.44 & 3.39 & 3.35 \\
\hline 9 & 5.12 & 4.26 & 3.86 & 3.63 & 3.48 & 3.37 & 3.29 & 3.23 & 3.18 & 3.14 \\
\hline 10 & 4.96 & 4.1 & 3.71 & 3.48 & 3.33 & 3.22 & 3.14 & 3.07 & 3.02 & 2.98 \\
\hline 11 & 4.84 & 3.98 & 3.59 & 3.36 & 3.2 & 3.09 & 3.01 & 2.95 & 2.9 & 2.85 \\
\hline 12 & 4.75 & 3.89 & 3.49 & 3.26 & 3.11 & 3 & 2.91 & 2.85 & 2.8 & 2.75 \\
\hline 13 & 4.67 & 3.81 & 3.41 & 3.18 & 3.03 & 2.92 & 2.83 & 2.77 & 2.71 & 2.67 \\
\hline 14 & 4.6 & 3.74 & 3.34 & 3.11 & 2.96 & 2.85 & 2.76 & 2.7 & 2.65 & 2.6 \\
\hline 15 & 4.54 & 3.68 & 3.29 & 3.06 & 2.9 & 2.79 & 2.71 & 2.64 & 2.59 & 2.54 \\
\hline 16 & 4.49 & 3.63 & 3.24 & 3.01 & 2.85 & 2.74 & 2.66 & 2.59 & 2.54 & 2.49 \\
\hline 17 & 4.45 & 3.59 & 3.2 & 2.96 & 2.81 & 2.7 & 2.61 & 2.55 & 2.49 & 2.45 \\
\hline 18 & 4.41 & 3.55 & 3.16 & 2.93 & 2.77 & 2.66 & 2.58 & 2.51 & 2.46 & 2.41 \\
\hline 19 & 4.38 & 3.52 & 3.13 & 2.9 & 2.74 & 2.63 & 2.54 & 2.48 & 2.42 & 2.38 \\
\hline 20 & 4.35 & 3.49 & 3.1 & 2.87 & 2.71 & 2.6 & 2.51 & 2.45 & 2.39 & 2.35 \\
\hline 21 & 4.32 & 3.47 & 3.07 & 2.84 & 2.68 & 2.57 & 2.49 & 2.42 & 2.37 & 2.32 \\
\hline 22 & 4.3 & 3.44 & 3.05 & 2.82 & 2.66 & 2.55 & 2.46 & 2.4 & 2.34 & 2.3 \\
\hline 23 & 4.28 & 3.42 & 3.03 & 2.8 & 2.64 & 2.53 & 2.44 & 2.37 & 2.32 & 2.27 \\
\hline 24 & 4.26 & 3.4 & 3.01 & 2.78 & 2.62 & 2.51 & 2.42 & 2.36 & 2.3 & 2.25 \\
\hline 25 & 4.24 & 3.39 & 2.99 & 2.76 & 2.6 & 2.49 & 2.4 & 2.34 & 2.28 & 2.24 \\
\hline 26 & 4.23 & 3.37 & 2.98 & 2.74 & 2.59 & 2.47 & 2.39 & 2.32 & 2.27 & 2.22 \\
\hline 27 & 4.21 & 3.35 & 2.96 & 2.73 & 2.57 & 2.46 & 2.37 & 2.31 & 2.25 & 2.2 \\
\hline 28 & 4.2 & 3.34 & 2.95 & 2.71 & 2.56 & 2.45 & 2.36 & 2.29 & 2.24 & 2.19 \\
\hline 29 & 4.18 & 3.33 & 2.93 & 2.7 & 2.55 & 2.43 & 2.35 & 2.28 & 2.22 & 2.18 \\
\hline 30 & 4.17 & 3.32 & 2.92 & 2.69 & 2.53 & 2.42 & 2.33 & 2.27 & 2.21 & 2.16 \\
\hline 35 & 4.12 & 3.27 & 2.87 & 2.64 & 2.49 & 2.37 & 2.29 & 2.22 & 2.16 & 2.11 \\
\hline 40 & 4.08 & 3.23 & 2.84 & 2.61 & 2.45 & 2.34 & 2.25 & 2.18 & 2.12 & 2.08 \\
\hline 45 & 4.06 & 3.2 & 2.81 & 2.58 & 2.42 & 2.31 & 2.22 & 2.15 & 2.1 & 2.05 \\
\hline 50 & 4.03 & 3.18 & 2.79 & 2.56 & 2.4 & 2.29 & 2.2 & 2.13 & 2.07 & 2.03 \\
\hline 100 & 3.94 & 3.09 & 2.7 & 2.46 & 2.31 & 2.19 & 2.1 & 2.03 & 1.97 & 1.93 \\
\hline
\end{tabular}

Table 15 - F distribution of Snedecor $(\alpha=0.05)$ 